\title{
Medical Treatment of Ulcerative Colitis
}

\author{
Uma Mahadevan, M.D. ${ }^{1}$
}

\begin{abstract}
Ulcerative colitis is a chronic inflammatory disease of the colon with an increasing incidence worldwide. The medical management of this disease continues to expand as drugs to induce and maintain remission are sought to avoid the need for colectomy. This article will review the standard of care for the treatment of mild, moderate, and severe ulcerative colitis. The efficacy, optimal usage, and adverse events profile of agents such as 5 -aminosalicylates, corticosteroids, azathioprine, and cyclosporine will be discussed and an algorithm for their use will be developed. Alternative and experimental therapies such as monoclonal antibodies, probiotics, and heparin will also be addressed.
\end{abstract}

KEYWORDS: Ulcerative colitis, medical therapy, cyclosporine

Objectives: Upon completion of this article, the reader should be able to: (1) summarize the standard therapies for mild, moderate, and severe ulcerative colitis; (2) develop an algorithm for the use of medications for the treatment of mild, moderate, and severe ulcerative colitis; and (3) list alternative therapies for ulcerative colitis that have anecdotal evidence of efficacy.

Ulcerative colitis (UC) is a chronic inflammatory disease of the colon that affects up to 12 per 100,000 people in Western countries. ${ }^{1}$ The incidence may be increasing in developing nations but is more frequent in Caucasians and people of Jewish descent. Although there is an increase in families, the genetic trend is not as strong as in Crohn's disease. ${ }^{2}$ The peak age of incidence is in persons between 15 and 30 years old. ${ }^{1}$ Protective factors against the development of UC include cigarette smoking ${ }^{3}$ and appendectomy. ${ }^{4}$

The distribution of disease at diagnosis varies widely. Estimates from a Norwegian study report proctitis in $32 \%$ of patients, left-sided colitis in $33 \%$, and more extensive colitis in $35 \% .{ }^{5}$ Thirty-nine percent of patients with proctosigmoiditis can expect extension of their disease ${ }^{6}$ and $90 \%$ of all UC cases can expect a relapsing course. ${ }^{7}$ Approximately 4 to $9 \%$ will require colectomy in the year of diagnosis, ${ }^{5,6}$ with a subsequent risk of colectomy at $1 \%$ per year. ${ }^{7}$ The majority of UC patients will require medical therapy chronically throughout their lifetime; therefore, an understanding of the appropriate use of these agents is important for the physician caring for these patients.

Prior to initiating therapy, a patient must be evaluated for extent and severity of disease. Extent of disease is best assessed by colonoscopy with biopsy of grossly affected as well as unaffected areas. If disease is distal to the splenic flexure, topical therapy such as suppositories and enemas may be the first choice. For more extensive disease, oral agents or a combination of oral and topical agents are indicated. The severity of disease can be assessed by the Truelove and Witts score ${ }^{8}$ (Table 1). This article will focus on medications for induction and maintenance of remission in mild to moderate UC as well as colectomy-sparing therapy for severe colitis.

Ulcerative Colitis; Editor in Chief, David E. Beck, M.D.; Guest Editor, Bruce G. Wolff, M.D. Clinics in Colon and Rectal Surgery, volume 17, number 1, 2004. Address for correspondence and reprint requests: Uma Mahadevan, M.D., UCSF/Mount Zion IBD Center, 2330 Post Street \#610, San Francisco, CA 94115. E-mail: umamah@itsa.ucsf.edu. ${ }^{1}$ Division of Gastroenterology, University of California, San Francisco, San Francisco, California. Copyright (C) 2004 by Thieme Medical Publishers, Inc., 333 Seventh Avenue, New York, NY 10001, USA. Tel: +1(212) 5844662. 1531-0043,p;2004,17,01,007,019,ftx,en;ccrs00156x. 
Table 1 Truelove and Witts' Criteria for Evaluating the Severity of Ulcerative Colitis ${ }^{8}$

\begin{tabular}{llll}
\hline Variable & Mild Disease & Severe Disease & Fulminant Disease \\
\hline Stools (number/day) & $<4$ & $>6$ & $>10$ \\
Blood in stool & Intermittent & Frequent & Continuous \\
Temperature $\left({ }^{\circ} \mathrm{C}\right)$ & Normal & $>37.5^{\circ}$ & $>37.5^{\circ}$ \\
Pulse (beats/minute) & Normal & $>90$ & $>90$ \\
Hemoglobin & Normal & $<75 \%$ of normal value & Transfusion required \\
Erythrocyte sedimentation rate $(\mathrm{mm} / \mathrm{hr})$ & $\leqslant 30$ & $>30$ & $>30$ \\
Colonic Features on x-ray & & Air, edematous wall, thumbprinting & Dilatation \\
Clinical signs & & Abdominal tenderness & Abdominal distention and tenderness \\
\hline
\end{tabular}

Moderate disease includes features of both mild and severe disease.

\section{AMINOSALICYLATES}

Sulfasalazine and 5-aminosalicylate (5-ASA) drugs are the first line in drug therapy for the treatment of mild to moderate UC. Table 2 summarizes the available agents. Type and dose of therapy are determined by location and severity of disease. For distal disease, topical therapy is the most effective method of delivery. By metanalysis, rectally administered 5-ASA is superior to placebo and rectal corticosteroids for induction and maintenance of remission in distal UC. ${ }^{9}$ If the patient has proctitis, 5-ASA suppositories at a dose of $500 \mathrm{mg}$ twice daily will induce and maintain remission. ${ }^{10,11}$ For disease up to the splenic flexure, 5-ASA enemas are effective for induction and maintenance of remission in doses of 2 to $4 \mathrm{~g}$ per enema. $^{12,13}$

For more extensive disease, multiple oral 5-ASA preparations are available. Sulfasalazine was the first 5-ASA agent found to be effective in UC. ${ }^{14}$ Placebocontrolled trials have shown that sulfasalazine is effective in inducing ${ }^{15,16}$ and maintaining ${ }^{17,18}$ remission in mild to moderate UC. However, its use is limited by high rates of intolerance among patients. Side effects can include headache, abdominal pain, nausea, vomiting, skin rash, fever, hepatitis, hematologic abnormalities, folate deficiency, pancreatitis, systemic lupus erythematosus, and male infertility. ${ }^{19}$ Sulfasalazine should always be given with folate $1 \mathrm{mg}$ daily and is contraindicated in men attempting conception. ${ }^{20}$

Sulfasalazine is a combination of 5-ASA azobound to the antibiotic sulfapyridine. It is the 5-ASA component that is the therapeutically active compound and the sulfapyridine moiety that is the cause of many of the side effects. ${ }^{21-23}$ This finding led to the development of alternative 5-ASA delivery systems for the treatment of UC and the discovery that it is the overall dose of mesalamine given, rather than the delivery system, that determines efficacy. Oral mesalamine agents with delayed- (Asacol) or timed-release (Pentasa) formulations at doses of 1.6 to $4.8 \mathrm{~g} /$ day are effective in inducing remission in mildly to moderately active UC. ${ }^{24-26}$ Doses of 0.8 to $4.8 \mathrm{~g} /$ day are effective in maintaining remission. Combination therapy, with oral mesalamine $2.4 \mathrm{~g} /$ day and rectal mesalamine $4 \mathrm{~g} /$ day, is more effective than either therapy alone. ${ }^{27}$ However, this may simply be a reflection of the overall dose of mesalamine received by the patient.

Olsalazine and balsalazide are 5-ASA agents that have diazo bonds, which are released by colonic bacteria. Olsalazine is effective for induction ${ }^{28,29}$ and maintenance ${ }^{30,31}$ of remission in UC, but its use is limited

Table 2 5-ASA Preparations

\begin{tabular}{llllc}
\hline Generic Name & Proprietary Names & 5-ASA Delivery Mechanism & Sites of Delivery & $\begin{array}{c}\text { Daily Dose, } \\
\text { Range }\end{array}$ \\
\hline Mesalamine & Rowasa, Salofalk & Enema suspension & Left colon and rectum & $1-4 \mathrm{~g}$ \\
Mesalamine & Canasa & Suppository & Rectum & $0.5-1.5 \mathrm{~g}$ \\
Mesalamine & Asacol & Eudragit-S coated tablets (release at $\mathrm{pH}>7$ & Terminal ileum, colon & $1.6-4.8 \mathrm{~g}$ \\
Mesalamine & Salofalk, Mesasal, & Mesalamine in sodium/glycerine buffer coated & Distal jejunum, proximal $\quad 1.5-4 \mathrm{~g}$ \\
& Claversal & with Eudragit- $\mathrm{L}$ (release at pH $>6$ ) & ileum & Entire small bowel, \\
Mesalamine & Pentasa & Ethylcellulose coated microgranules (time & colon & Colon \\
Sulfasalazine & Azulfidine & and pH dependant release) & Colon & $1-4 \mathrm{~g}$ \\
Olsalazine & Dipentum & 5-ASA azo-bound to sulfapyridine & Colon & $1-3 \mathrm{~g}$ \\
Balsalazide & Colazaal & 5-ASA dimer linked by azo-bond & & $2-6.75 \mathrm{~g}$ \\
\hline
\end{tabular}


by worsened diarrhea. ${ }^{32}$ Balsalazide is composed of a 5-ASA linked to an inert carrier molecule. Although one study did show significant efficacy of balsalazide over an equivalent dose of mesalamine, ${ }^{33}$ other studies have shown an efficacy equal to sulfasalazine ${ }^{34}$ and mesalamine ${ }^{35,36}$ for induction of remission in mild to moderate UC.

Though 5-ASA agents are considered safe, some toxicity can be seen. Aside from the complications attributed to sulfasalazine above, the most frequently reported side effects of 5-ASA agents include dizziness, fever, headache, abdominal pain, nausea, and rash. ${ }^{25,26}$ Rare but serious adverse events include pulmonary toxicity, pericarditis, hepatitis, pancreatitis, aplastic anemia, leukopenia, and thrombocytopenia. ${ }^{37-40}$ Though interstitial nephritis has been reported, ${ }^{41}$ the frequency of renal insufficiency was low in large safety and pharmacovigilance databases for Asacol and Pentasa. ${ }^{42,43} \mathrm{Fi}^{-}$ nally, a minority of patients will experience worsening diarrhea and abdominal pain due to a hypersensitivity reaction to 5 -aminosalicylate. ${ }^{43 a}$

In summary, 5-ASA agents are safe and effective for the induction and maintenance of remission in mild to moderate UC. Its use in severe colitis is not well studied. Data support the concept that the optimum use of aminosalicylates in active UC demands the highest tolerated dose, whether administered orally, rectally, or in combination. In quiescent disease, lower doses may be more tolerable to the patient and are less costly, although again, there is the general theme of dose response.

\section{CORTICOSTEROIDS}

The discovery that corticosteroids were effective in UC had a significant positive impact on a disease with a previous high mortality. Mortality rates dropped from a high of $61 \%{ }^{44}$ to 4 to $7 \% .{ }^{45}$ However, today the side effects of corticosteroids make it a less desirable though sometimes unavoidable agent in the therapy of UC.

In a population-based study in Olmstead County, Minnesota, 34\% of UC patients required corticosteroids at some point in their disease course. ${ }^{46}$ Therapy with corticosteroids resulted in complete remission in 54\%, partial remission in $30 \%$, and no response in $16 \%$. At 1 year from initiation of corticosteroid therapy, prolonged response without steroids or surgery was seen in $49 \%$, corticosteroid dependence in $22 \%$, and surgery in $29 \%$.

Resistance to corticosteroids is seen in 16 to $20 \%$ of patients. ${ }^{46,47}$ Several potential mechanisms for resistance to corticosteroid therapy in patients with inflammatory bowel disease (IBD) have been described, including an increase in the expression of glucocorticoid receptor $\beta^{48}$ and increased expression of the multidrug resistance-1 gene (MDR-1). The latter results in an increased expression of the membrane-based drug efflux pump P-glycoprotein 170 that pumps corticosteroids out of cells, thus lowering the intracellular concentration. $^{49}$

Corticosteroids can be administered as oral (cortisone, prednisone, prednisolone, budesonide), intravenous (prednisolone, methylprednisolone, corticotropin), or rectal (beclomethasone, tixicortol, budesonide, prednisolone metasulfobenzoate) formulations. Truelove and Witts reported the efficacy of cortisone $100 \mathrm{mg}$ per day in UC in $1955 .{ }^{8}$ Baron and colleagues then reported that $40 \mathrm{mg}$ of prednisone was more effective than $20 \mathrm{mg}$ and equally effective as $60 \mathrm{mg}$, but with fewer side effects. ${ }^{50}$ Finally, single daily dosing of prednisone $40 \mathrm{mg}$ daily was equally effective as $10 \mathrm{mg}$ four times a day. ${ }^{51} \mathrm{It}$ is from these early studies that the current maxim of prednisone $40 \mathrm{mg}$ per day for moderate to severe UC originated. No maintenance benefit of corticosteroids in UC has been found. ${ }^{52}$

Rectal corticosteroids are effective in left-sided UC. They provide quick relief for patients with tenesmus and bleeding. Rectal hydrocortisone $100 \mathrm{mg}^{53}$ and prednisolone $10 \mathrm{mg}^{54}$ have been proven effective by controlled trials for induction of remission, but not for maintenance. ${ }^{55}$ Budesonide enemas, which have minimal systemic absorption, are also effective for induction but not for maintenance of remission in left-sided UC. ${ }^{56}$ However, by metanalysis, topical corticosteroids were not as effective as topical mesalamine therapies for ulcerative proctitis and left-sided UC. ${ }^{57}$ Also, rectal corticosteroids are well absorbed and can result in suppression of the adrenal axis. ${ }^{58}$

Prednisone and prednisolone are well absorbed after oral administration and bioavailability is high, averaging over $70 \%$. However, the absorption may be decreased in patients with severe UC in whom oral administration of prednisolone resulted in a lower peak plasma concentration and a slower rate of decrease in the plasma concentration compared with healthy volunteers. ${ }^{59}$ Patients with severe UC who receive $60 \mathrm{mg} /$ day of intravenous prednisolone have a $73 \%$ response rate in 5 days. ${ }^{60}$ Some patients are slower responders and will require 7 to 10 days to respond. No controlled trials have addressed the effectiveness of single, multiple, or continuous infusion of corticosteroids in severe UC. ${ }^{61}$ Intramuscular corticotropin (adrenal corticotropin hormone, ACTH) at $80 \mathrm{U} /$ day showed a similar benefit to cortisone $200 \mathrm{mg} /$ day in patients with active UC. ${ }^{55} \mathrm{In}$ severe UC, corticotropin 80 to $120 \mathrm{U} /$ day was similar to hydrocortisone 300 to $400 \mathrm{mg} /$ day. ${ }^{62-64}$ However, some deaths were reported in IV ACTH due to adrenocortical necrosis. ${ }^{64}$

Corticosteroid toxicity is frequent and often results in resistance on the part of patients to reinitiate therapy if they have used it before. Short-term toxicities observed include moon face (47\%), acne (30\%), infection (27\%), ecchymoses (17\%), hypertension (15\%), 
Table 3 Adverse Effects Associated with Systemic Corticosteroid Therapy

\begin{tabular}{ll}
\hline Cutaneous & Atrophy, striae, vascular effects, purpura, alopecia, pigmentation, acne, easy bruising \\
Cardiovascular & Hypertension, edema, atherosclerosis \\
Gastrointestinal & Nausea, vomiting, intestinal perforation, pancreatitis, esophagitis \\
Gynecological/obstetrical & Amenorrhea, gestational diabetes, adrenal suppression of infant \\
Neuropsychiatric & $\begin{array}{r}\text { Psychosis, peripheral neuropathy, pseudotumor cerebri, depression/mood disorders, impaired cognitive } \\
\text { function, seizures, insomnia, irritability } \\
\text { Metabolic }\end{array}$ \\
Musculoskeletal & Osteoporosis/osteopenia, aseptic necrosis, growth retardation, muscle atrophy, myopathy \\
Hematological & Leukocytosis, lymphopenia, eosinophenia, infection, immunosuppression, impaired fibroplasia, \\
& decreased mitotic rate \\
Ophthalmalogical & Cataracts, glaucoma, infection, exophthalmoses, hemorrhage \\
Endocrine & Hypothalamic-pituitary-adrenal axis suppression, hirsutism, moon facies \\
Pediatric & Growth retardation \\
\hline
\end{tabular}

Adapted from Yang and Lichtenstein ${ }^{163}$ with permission.

hirsutism (7\%), petechial bleeding (6\%), and striae (6\%). Prolonged corticosteroid therapy can result in multiple serious side effects including hypertension, new onset diabetes mellitus, infection, osteonecrosis, steroid associated osteoporosis, myopathy, psychosis, cataracts, and glaucoma. ${ }^{65-67}$ Table 3 lists potential side effects of corticosteroid therapy.

For moderate to severe UC, the preferred initial prednisone dose is $40 \mathrm{mg} /$ day administered as a single dose. The optimal tapering strategy has not been determined, but experienced clinicians will typically treat the patient with prednisone $40 \mathrm{mg} /$ day for 2 to 4 weeks, then taper by $5 \mathrm{mg} /$ week to a daily dose of $20 \mathrm{mg} /$ day, then slow the taper to $2.5 \mathrm{mg}$ /week until prednisone is discontinued. For severe UC, requiring hospitalization, hydrocortisone 300 to $400 \mathrm{mg} /$ day or methylprednisolone 40 to $60 \mathrm{mg} /$ day is used. Five to seven days are required prior to determining whether the patient has failed steroids.

\section{ANTIBIOTICS}

The lack of efficacy of antibiotics in the treatment of UC and Crohn's disease is somewhat surprising given the presumed role of bacteria in the etiology of IBD. One placebo-controlled trial of ciprofloxacin in moderately active UC showed benefit ${ }^{68}$ while another was negative. ${ }^{69}$ The addition of intravenous ciprofloxacin to steroids in severe UC was also not of benefit. ${ }^{70}$ Oral tobramycin had short-term efficacy ${ }^{71}$ in UC but could not maintain remission. ${ }^{72}$ In acute severe UC, the combination of tobramycin and metronidazole, ${ }^{73}$ oral vancomycin alone, ${ }^{74}$ or intravenous metronidazole alone ${ }^{75}$ were not of added benefit to corticosteroids. Finally, in a small placebo-controlled trial, rifaximin, a nonabsorbed, broad-spectrum antibiotic, was not statistically better than placebo in overall clinical outcome in patients with steroid-refractory severe UC, but did have a significant reduction in stool frequency, rectal bleed- ing, and sigmoidoscopic score compared with placebo. ${ }^{76}$ Larger trials are underway.

Antibiotics should not be used without evidence of infection in patients with mild to moderate UC. Although evidence does not support their use in severe $\mathrm{UC}$, in clinical practice the hospitalized patient may receive antibiotics as prophylaxis against bacterial translocation in the severely inflamed colon.

\section{PROBIOTICS}

Probiotics are live nonpathogenic organisms that confer health benefits by improving the microbial balance. While the formulation VSL3 has shown clear benefit for prevention of pouchitis after ileal-pouch surgery ${ }^{77}$ and maintenance of remission in chronic pouchitis, ${ }^{78}$ their benefit and that of other probiotics formulations in UC are still to be proven. Two small controlled studies have shown that $E$. coli Nissle is effective for maintenance of remission in UC. ${ }^{79,80}$ An open label trial of VSL3 in mildly to moderately active UC demonstrated a remission rate of $63 \%$. However, patients were on other agents such as mesalamine and steroids. ${ }^{81}$ Larger controlled trials are needed to prove efficacy in both induction and maintenance of remission in UC.

\section{NICOTINE}

Nonsmokers and former smokers have higher rates of UC than current smokers. ${ }^{3}$ Also, smokers with UC who stop smoking experience increased severity of disease. ${ }^{82}$ The mechanism of this effect is thought to be due to nicotine, but is not completely elucidated. ${ }^{83,84}$ Placebocontrolled trials of transdermal nicotine patches demonstrated efficacy in achieving clinical remission or improvement at doses of $25 \mathrm{mg} / 24$ hours $^{85}$ and $22 \mathrm{mg} /$ 24 hours. ${ }^{86}$ However, it was not effective for maintenance, ${ }^{87}$ although an uncontrolled study suggested that patients who are treated with transdermal nicotine 
maintain their response longer than those treated with corticosteroids. ${ }^{88}$ Nicotine enemas also demonstrated benefit in uncontrolled trials. ${ }^{89,90}$ The major drawback of nicotine use is the high percentage of side effects, especially in patients who have never smoked before. These side effects include skin irritation, lightheadedness, nausea, vomiting, diaphoresis, central nervous system disturbances, and insomnia. ${ }^{84}$

\section{IMMUNOSUPPRESSANTS}

While 5-ASA agents are the first line for induction and maintenance of remission in mild to moderate $\mathrm{UC}$ and steroids are used for induction of remission in moderate to severe UC, immune modifier drugs are used to induce remission in steroid-dependent or steroid-refractory disease, maintain remission in those patients for whom 5-ASA agents are inadequate, and as salvage therapy in severe disease refractory to steroid therapy.

\section{Azathioprine / 6-Mercaptopurine}

6-mercaptopurine (6-MP) and its prodrug azathioprine (AZA) are purine antimetabolite drugs demonstrated to be effective for the induction and maintenance of remission in UC and have proven steroid-sparing effects. The efficacy of 6-MP was recognized as early as 1962 in a case report by Bean. ${ }^{91}$ Though some controlled studies of AZA versus placebo and AZA versus sulfasalazine in the treatment of acute attacks of colitis found no significant benefit, ${ }^{89,92}$ others found that AZA use resulted in improved disease activity, a decreased need for steroids, ${ }^{93}$ and prolonged rates of remission. ${ }^{94}$ Multiple uncontrolled studies confirmed the benefits of AZA/6-MP..$^{95-99}$

Effective doses of AZA are 2.0 to $3.0 \mathrm{mg} / \mathrm{kg} /$ day and of 6-MP are 1.0 to $1.5 \mathrm{mg} / \mathrm{kg} /$ day and may take up to 17 weeks to take complete effect. ${ }^{100}$ Though some physicians begin at low doses and titrate upwards, our practice is to begin at full dose with careful monitoring of the compete blood count. There is no role for intravenous loading of AZA in severe UC. ${ }^{101}$ Thiopurine S-methyltransferase (TPMT) phenotype or genotype can aid in determining safety and optimal dosage of AZA/6-MP. Low to intermediate levels of TPMT are associated with leukopenia in rheumatoid arthritis ${ }^{102}$ and with Crohn's disease. ${ }^{103}$ Based on these observations, it is recommended that patients with normal TPMT activity receive standard doses of AZA or 6-MP. Patients with intermediate activity should receive $50 \%$ of the standard dose and those who have no TPMT activity should not be treated with the drug. ${ }^{104}$ The use of metabolite levels (6-TGN [thioguanine nucleotides] and 6-MMP [6-methylmercaptopurine]) to gauge optimal dosing of AZA/6-MP is controversial. Though two studies supported its use, ${ }^{105,106}$ three others failed to demonstrate a consistent relationship between clinical efficacy and erythrocyte 6-TGN concentrations. ${ }^{107-109}$

Allergic reactions occur in 5\% of patients taking AZA or 6-MP and include pancreatitis, fever, rash, malaise, nausea, diarrhea, and some cases of hepatitis. ${ }^{110}$ Nonallergic reactions include bone marrow suppression leading to leukopenia, anemia or thrombocytopenia, opportunistic infection, and hepatitis. Lymphoma does not appear to be increased above what is expected in IBD, ${ }^{110-112}$ though there may be an increase in EpsteinBarr virus-associated lymphomas in patients treated with AZA/6-MP. ${ }^{113}$

\section{Methotrexate}

Methotrexate (MTX) has demonstrated benefit for the induction and maintenance of remission in Crohn's disease ${ }^{114,115}$; however, its benefit in UC is not well established. Uncontrolled data have shown response in small series of patients with UC. ${ }^{116-118}$ The only controlled trial in UC was by Oren and associates, ${ }^{119}$ which compared oral MTX $12.5 \mathrm{mg} /$ week with placebo in 67 patients with chronic active UC. No difference was found between the MTX and placebo group in remission and relapse rates. A recent study reported on patients with steroid-dependent or steroid-resistant active UC. ${ }^{120}$ Ten patients were intolerant or resistant to AZA and were switched to MTX $12.5 \mathrm{mg}$ IM/ week. Six of 10 (60\%) achieved clinical remission, 40\% achieved clinical response, and $20 \%$ subsequently relapsed. Available data suggest that AZA/6-MP should be the first choice for maintenance and steroid sparing in UC, but MTX can be tried in those who are intolerant or resistant to AZA/6-MP. Our usual starting dose is $25 \mathrm{mg} \mathrm{SQ} /$ week, though once remission is achieved, $15 \mathrm{mg} \mathrm{SQ} /$ week can be used for maintenance.

MTX should always be given with folic acid $1 \mathrm{mg}$ per day. Use in patients who are diabetic, obese, use excessive alcohol, or have known liver abnormalities is contraindicated. MTX is teratogenic and should not be used in men or women attempting conception. Increased serum transaminases and hypersensitivity reactions such as rash and pneumonitis can sometimes be seen.

\section{Cyclosporine}

Cyclosporine (CSA) is a calcineurin inhibitor that is used as salvage therapy for induction of remission in severe, steroid-refractory UC that would otherwise require colectomy. There are four randomized trials that have demonstrated the efficacy of CSA in severe UC. The first, by Lichtiger et al, found that 9/11 (82\%) steroid-refractory UC patients had clinical response with $4 \mathrm{mg} / \mathrm{kg} /$ day of CSA in combination with intravenous steroids, versus none of placebo-treated patients on intravenous steroids alone. ${ }^{121}$ Two other controlled studies 
suggested that CSA alone at a dose of $4 \mathrm{mg} / \mathrm{kg} /$ day without steroids is effective in inducing remission in severe UC. ${ }^{122,123}$ Finally, a study by Van Assche and colleagues found that $2 \mathrm{mg} / \mathrm{kg} /$ day of CSA is equivalent to $4 \mathrm{mg} / \mathrm{kg} /$ day in achieving response in severe UC. ${ }^{124}$

Patients who respond to $4 \mathrm{mg} / \mathrm{kg} /$ day of IV CSA are continued on the drug for 7 to 10 days. The target whole blood CSA level is 300 to $350 \mathrm{ng} / \mathrm{ml}$ for the $4 \mathrm{mg} / \mathrm{kg} /$ day dose or 150 to $250 \mathrm{ng} / \mathrm{ml}$ for the $2 \mathrm{mg} /$ $\mathrm{kg} /$ day dose. They are then converted to oral CSA at a dose of $8 \mathrm{mg} / \mathrm{kg} /$ day or twice the IV dose in hospital. ${ }^{125}$ The desired CSA level on oral dose is 150 to $300 \mathrm{ng} / \mathrm{ml}$. Unfortunately, $45 \%$ of patients on oral CSA alone will require colectomy at 6 months. ${ }^{126}$ This can be decreased to $20 \%$ by the addition of $6-\mathrm{MP} / \mathrm{AZA}$ at discharge from the hospital. ${ }^{126}$ Patients are also continued on prednisone, which is tapered during outpatient follow-up. This regimen of triple immunosuppressive therapy with CSA, 6-MP/AZA, and prednisone can lead to significant infectious complications. For this reason, trimethoprim/ sulfamethoxazole is added for prophylaxis. One uncontrolled study suggested that patients responding to IV CSA can be started on oral AZA without oral CSA, and prednisone can be tapered accordingly ${ }^{127}$; however, the colectomy rate was $41 \%$.

An oral, microemulsion form of CSA (Neoral) has been developed which has increased oral bioavailability and improved absorption from the small bowel. ${ }^{128}$ The pharmokinetic parameters of CSA microemulsion in patients with IBD appear to be similar to those of healthy volunteers. ${ }^{129}$ Three small series have described efficacy of oral microemulsion CSA in severe UC, ${ }^{130-132}$ though larger controlled trials are needed.

In a report from Mount Sinai Hospital on 111 IBD patients treated with CSA, the most frequent adverse events were paresthesias (51\%), hypertension (43\%), hypertrichosis (27\%), renal insufficiency (23\%), infections (20\%), gingival hyperplasia (4\%), seizures (3\%), death (2\%), and anaphylaxis (1\%). ${ }^{133}$ In a similar report from the University of Chicago on 74 patients with IBD treated with CSA, 54\% experienced adverse events including severe events such as Pneumocystis carinii pneumonia in two patients, abdominal abscess, grand mal seizure, mycotic aneurysm, and renal insufficiency. ${ }^{126}$ Table 4 lists drug interactions of CSA and tacrolimus.

CSA in severe UC is definitely effective, but its side-effect profile and tangible long-term failure rate must be discussed in depth with the patient debating colectomy versus salvage medical therapy. Also, patients who are not tolerant of AZA/6-MP are not good candidates for CSA therapy, as CSA alone has a high colectomy rate over time. Side effects may be decreased by using lower doses of IV CSA at $2 \mathrm{mg} / \mathrm{kg} /$ day, using antibiotic prophylaxis, or avoiding triple therapy with oral CSA, AZA and prednisone.
Table 4 Potential Drug Interactions of Cyclosporine and Tacrolimus

\begin{tabular}{ll}
\hline Inhibition of cytochrome P450 & Calcium channel blockers \\
Increased CSA levels & Bromocriptine \\
& Metoclopramide \\
& Imidazoles \\
& Macrolide antibiotics \\
& Methylprednisolone \\
& Protease inhibitors \\
& Grapefruit juice \\
Induction of cytochrome P450 & Rifampin \\
Decrease cyclosporine levels & Phenobarbital \\
& Phenytoin \\
& Carbamazepine \\
& Reverse transcriptase \\
& inhibitors \\
& St. John's wort \\
\hline
\end{tabular}

Adapted from Kornbluth, et al ${ }^{125}$ with permission.

\section{Tacrolimus}

Tacrolimus is a calcineurin inhibitor like CSA. Controlled trials in severe UC have not been conducted to date, but multiple case series suggest efficacy. The first study was by Bousvaros et $\mathrm{al}^{134}$ and described a $69 \%$ clinical response rate in 13 patients with steroid-refractory UC. However, at 1 year, only 38\% of patients avoided colectomy. Three case series note salvage therapy with tacrolimus in steroid-resistant or steroiddependent $\mathrm{UC}^{135,136}$ as well as in a patient with toxic megacolon. ${ }^{137}$ One trial compared intravenous to oral tacrolimus in 38 patients with refractory UC. ${ }^{138}$ Oral and IV dosing was equivalent. Eighteen of 38 patients (47\%) improved within 14 days. Thirty-five of 38 patients (92\%) avoided colectomy at 28 days, but at 2 years, the colectomy rate was $50 \%$.

The dose of oral tacrolimus is 0.1 to $0.2 \mathrm{mg} / \mathrm{kg} /$ day given in divided doses twice daily. The serum trough levels are 4 to $6 \mathrm{ng} / \mathrm{ml}$. Patients should be monitored closely for evidence of infections and trimethoprim/ sulfamethoxazole prophylaxis should be used. Side effects include transient renal insufficiency, tremor, paresthesias, hyperkalemia, and hypertension. ${ }^{135}$ These often resolve with lowering of the dose.

\section{Infliximab}

Infliximab is a chimeric monoclonal antibody to tumor necrosis factor- $\alpha$ (TNF), a key inflammatory cytokine. While infliximab has made a dramatic impact on the treatment of Crohn's disease, ${ }^{139}$ its role in UC is not clear. Sands and associates reported 11 patients in a controlled trial of infliximab in severe, steroid-refractory UC. ${ }^{140}$ Four of eight patients (50\%) who received infliximab had a clinical response, although one subsequently 
required colectomy. Two small case series report response in severe UC, ${ }^{141,142}$ but a larger randomized controlled trial was negative. ${ }^{143}$ In this latter trial, patients with severe, steroid-refractory UC were randomized to infliximab $5 \mathrm{mg} / \mathrm{kg}$ or placebo at weeks 0 and 2. After 6 weeks, remission was achieved in $8 / 22$ infliximab patients and $6 / 20$ placebo (not significant). A controlled trial of infliximab in nonsteroid-refractory patients ${ }^{144}$ randomized patients to either infliximab $5 \mathrm{mg} / \mathrm{kg}$ at 0,2 , and 6 weeks or intravenous prednisolone at $1.5 \mathrm{mg} / \mathrm{kg}$ daily for 2 weeks followed by a taper. Five of 6 patients receiving infliximab and $6 / 7$ patients receiving steroids had a response. The two agents appear to be equivalent in this small study.

Clinical experience and a placebo-controlled trial $^{143}$ suggest that infliximab is not effective in steroid-refractory UC. This is further supported by a retrospective analysis of 27 patients with active UC who received infliximab. ${ }^{145}$ While $44 \%$ of all UC patients achieved remission and $22 \%$ had a partial response, steroid-refractory patients were less likely to respond when compared with steroid-responsive patients (33\% vs $83 \% ; p=0.026$ ). Infliximab should not be used in severe, steroid-refractory UC. Evidence for its use in steroidresponsive disease is anecdotal at best and controlled studies are needed.

\section{EXPERIMENTAL AGENTS}

\section{Heparin}

Thrombotic events associated with UC and histologic evidence of microvascular thrombosis on colon biopsy suggested that anticoagulation may be an effective therapy for UC. ${ }^{146}$ Uncontrolled studies did find unfractionated heparin to be of benefit, ${ }^{147,148}$ but small controlled studies comparing unfractionated heparin to corticosteroids had mixed results. ${ }^{149,150}$ Larger, placebo-controlled trials of low-molecular-weight heparin in studies of 100 patients and 138 patients, respectively, found no significant benefit over placebo. ${ }^{151,152}$ Heparin is not effective for the treatment of UC but does appear to be safe with no increased risk of gastrointestinal bleeding, should the need for anticoagulation for other reasons arise in these patients.

\section{BIOLOGICS: CYTOKINES AND ANTIBODIES}

Investigational agents with preliminary reports of efficacy include vepolimomab (monoclonal antibody $[\mathrm{mAb}]$ to vascular adhesion protein-1) ${ }^{153}$; interleukin-2 (IL-2) antagonists such as basiliximab, which may increase response to steroids in steroid-resistant $\mathrm{UC}^{154}$; antiCD3 antibodies, such as visilizumab, which has shown preliminary efficacy in steroid-resistant $\mathrm{UC}^{155}$; antibody to $\alpha 4 \beta 7$, such as MLN-02, which mediates recruitment of lymphocytes to the gut and demonstrated safety and efficacy in a controlled trial in patients with active $\mathrm{UC}^{156}$; and interferon- $\beta$, which showed some clinical response in patients with steroid-refractory $\mathrm{UC}$ in a phase II, placebo-controlled trial. ${ }^{157}$ Multiple other agents exist, but for all new agents, while preliminary results are exciting, randomized controlled trials are needed before widespread use is initiated.

\section{LEUKOCYTAPHERESIS}

One novel technique for the treatment of severe UC is leuckocytapheresis. Based on the theory that inflammation and damage to the colonic mucosa are caused by products of activated granulocytes, monocytes, and macrophages, an extracorporeal leukocytapheresis column (LCAP) was developed to remove these cells from the peripheral circulation, with reported efficacy in UC. ${ }^{158}$ A randomized controlled trial in 76 active UC patients reported that addition of LCAP to corticosteroids improved clinical response with a reduction in steroid dosage. ${ }^{159}$ These results were corroborated by a recent randomized trial from the same group showing that LCAP was more effective than sham perfusion $(80 \%$ vs $33 \% ; p<0.05)$ in eliciting clinical response in patients with active UC. ${ }^{160}$

\section{ALGORITHM FOR THE TREATMENT OF ULCERATIVE COLITIS}

Figure 1 outlines the algorithm for the treatment of a flare of UC. When a patient presents with a flare, the diagnosis should be confirmed and the severity of the disease established. Colonoscopy with biopsy to confirm the diagnosis of UC and establish the extent of the disease should be performed in all new and established cases. A small bowel follow-through should be performed once at some point in the disease course to rule out the diagnosis of Crohn's disease. Stool studies should be sent in all acute flares to rule out superinfection with Clostridium difficile, bacteria, or ova and parasites. In a patient with severe UC, an unprepped flexible sigmoidoscopy rather than full colonoscopy should be performed with biopsies of the rectum for histology and viral culture. This will confirm the severity of the disease and will also rule out cytomegalovirus (CMV). One study reported that $36 \%$ of patients with steroid-refractory colitis had CMV on rectal specimens. ${ }^{161}$ The majority of these patients responded to antiviral therapy with foscarnet or ganciclovir. The severity of the disease can be determined by the Truelove and Witts score (Table 1).

For mild to moderate disease the first-line therapy is 5-ASA agents. If this is ineffective, steroids can be used to induce remission. If the patient cannot be tapered off the steroids or relapses after steroid withdrawal, immunosuppression with AZA/6-MP should be initiated for steroid-sparing and maintenance effects. 


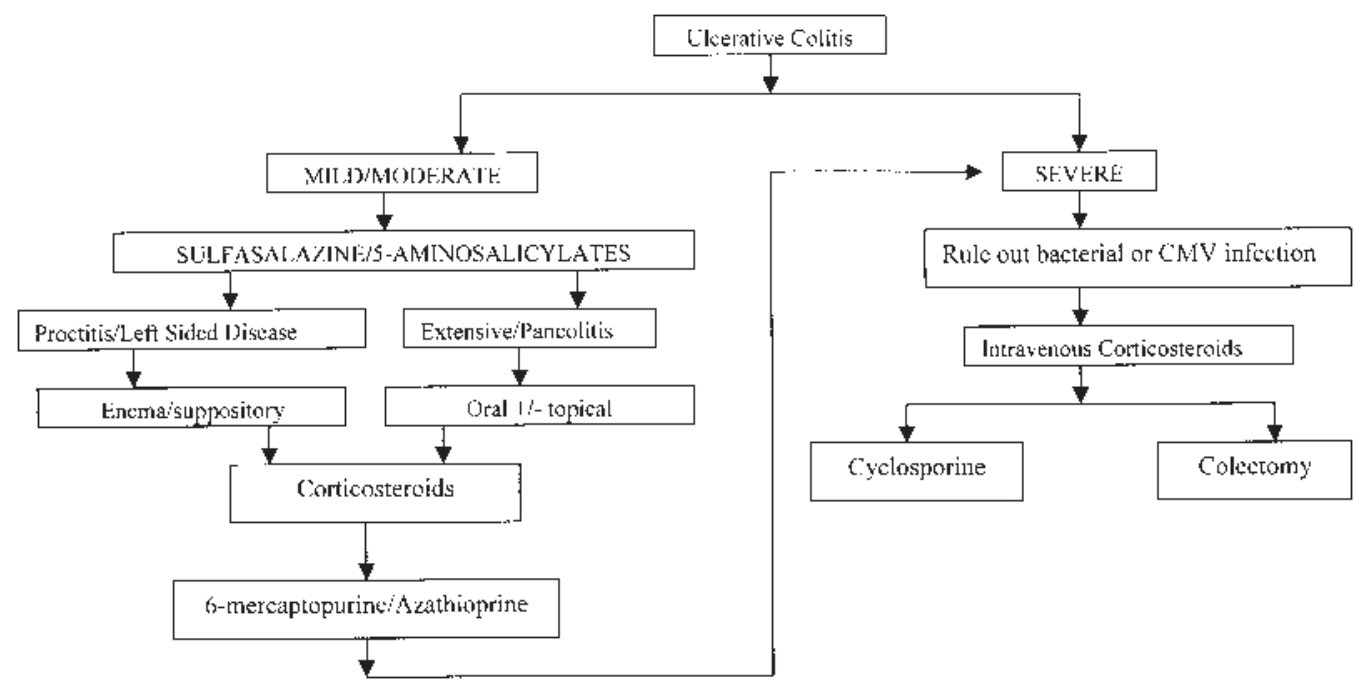

Figure 1 An algorithm for the medial management of mild, moderate, and severe ulcerative colitis. Progression along arrows is indicated if prior therapies fail.

In the patient with severe disease not responding to oral steroids, intravenous steroids are indicated in an inpatient setting. If there is no response after 5 to 7 days, CSA should be offered if the patient is an appropriate candidate. Patients who are intolerant of AZA/6-MP are not good candidates as colectomy rates are high in patients on CSA alone. Theoretically, MTX can be used instead, though its use in UC has less supportive evidence. Patient reluctance to use CSA or failure to respond to CSA would then lead to colectomy.

Aggressive medical therapy with immunosuppressants does not increase the risk of postoperative complications after colectomy and ileal pouch-anal anastomosis. ${ }^{162}$ Factors that predicted an increase in shortterm complications were high-dose steroids and severe disease. Variations on this algorithm with experimental or anecdotal agents can be tried as long as the patient is fully informed and the physician is comfortable with these drugs. However, larger controlled trials are needed before widespread use can be adopted.

\section{REFERENCES}

1. Andres PG, Friedman LS. Epidemiology and the natural course of inflammatory bowel disease. Gastroenterol Clin North Am 1999;28:255-281

2. Halfvarson J, Bodin L, Tysk C, Lindberg E, Jarnerot G. Inflammatory bowel disease in a Swedish twin cohort: a long-term follow-up of concordance and clinical characteristics. Gastroenterology 2003;124:1767-1773

3. Harries AD, Baird A, Rhodes J. Non-smoking: a feature of ulcerative colitis. Br Med J (Clin Res Ed) 1982;284:706

4. Andersson RE, Olaison G, Tysk C, Ekbom A. Appendectomy and protection against ulcerative colitis. N Engl J Med 2001;344:808-814

5. Moum B, Vatn MH, Ekbom A, et al. Incidence of inflammatory bowel disease in southeastern Norway: evalua- tion of methods after 1 year of registration. Southeastern Norway IBD Study Group of Gastroenterologists. Digestion 1995;56:377-381

6. Langholz E, Munkholm P, Davidsen M, Binder V. Course of ulcerative colitis: analysis of changes in disease activity over years. Gastroenterology 1994;107:3-11

7. Langholz E, Munkholm P, Davidsen M, Nielsen $\mathrm{OH}$, Binder V. Changes in extent of ulcerative colitis: a study on the course and prognostic factors. Scand J Gastroenterol 1996;31:260-266

8. Truelove SC, Witts L. Cortisone in ulcerative colitis: final report on a therapeutic trial. BMJ 1955;2:1041-1048

9. Marshall JK, Irvine EJ. Rectal aminosalicylate therapy for distal ulcerative colitis: a meta-analysis. Aliment Pharmacol Ther 1995;9:293-300

10. D'Arienzo A, Panarese A, D'Armiento FP, et al. 5aminosalicylic acid suppositories in the maintenance of remission in idiopathic proctitis or proctosigmoiditis: a double-blind placebo-controlled clinical trial. Am J Gastroenterol 1990;85:1079-1082

11. Campieri M, De Franchis R, Bianchi Porro G, Ranzi T, Brunetti G, Barbara L. Mesalazine (5-aminosalicylic acid) suppositories in the treatment of ulcerative proctitis or distal proctosigmoiditis. A randomized controlled trial. Scand J Gastroenterol 1990;25:663-668

12. Sutherland LR, Martin F, Greer S, et al. 5-aminosalicylic acid enema in the treatment of distal ulcerative colitis, proctosigmoiditis, and proctitis. Gastroenterology 1987;92: 1894-1898

13. d'Albasio G, Trallori G, Ghetti A, et al. Intermittent therapy with high-dose 5-aminosalicylic acid enemas for maintaining remission in ulcerative proctosigmoiditis. Dis Colon Rectum 1990;33:394-397

14. Svartz N. Salazopyrine, a new sulfanilamide preparation. Acta Med Scand 1942;110:557

15. Dick AP, Grayson M, Carpenter RG, Petrie A. Controlled trial of sulphasalazine in the treatment of ulcerative colitis. Gut 1964;50:437-442

16. Baron JH, Connell A, Lennard-Jones JE, Jones FA. Sulphasalzine and salicylazosulphadimidine in ulcerative colitis. Lancet 1962;1:1094-1096 
17. Misiewicz JJ, Lennard-Jones JE, Connell AM, Baron JH, Avery Jones F. Controlled trial of sulphasalazine in maintenance therapy for ulcerative colitis. Lancet 1965; 1:185-188

18. Dissanayake AS, Truelove SC. A controlled therapeutic trial of long-term maintenance treatment of ulcerative colitis with sulphazalazine (Salazopyrin). Gut 1973;14:923-926

19. Taffet SL, Das KM. Sulfasalazine. Adverse effects and desensitization. Dig Dis Sci 1983;28:833-842

20. O'Morain C, Smethurst P, Dore CJ, Levi AJ. Reversible male infertility due to sulphasalazine: studies in man and rat. Gut 1984;25:1078-1084

21. Das KM, Eastwood MA, McManus JP, Sircus W. The metabolism of salicylazosulphapyridine in ulcerative colitis. I. The relationship between metabolites and the response to treatment in inpatients. Gut 1973;14:631-641

22. Klotz U, Maier K, Fischer C, Heinkel K. Therapeutic efficacy of sulfasalazine and its metabolites in patients with ulcerative colitis and Crohn's disease. N Engl J Med 1980; 303:1499-1502

23. Khan AK, Piris J, Truelove SC. An experiment to determine the active therapeutic moiety of sulphasalazine. Lancet 1977; 2:892-895

24. Hanauer S, Schwartz J, Robinson M, et al. Mesalamine capsules for treatment of active ulcerative colitis: results of a controlled trial Pentasa Study Group. Am J Gastroenterol 1993;88:1188-1197

25. Sninsky CA, Cort DH, Shanahan F, et al. Oral mesalamine (Asacol) for mildly to moderately active ulcerative colitis. A multicenter study. Ann Intern Med 1991;115:350-355

26. Schroeder KW, Tremaine WJ, Ilstrup DM. Coated oral 5-aminosalicylic acid therapy for mildly to moderately active ulcerative colitis. A randomized study. N Engl J Med 1987; 317:1625-1629

27. Safdi M, DeMicco M, Sninsky C, et al. A double-blind comparison of oral versus rectal mesalamine versus combination therapy in the treatment of distal ulcerative colitis. Am J Gastroenterol 1997;92:1867-1871

28. Rao SS, Dundas SA, Holdsworth CD, Cann PA, Palmer $\mathrm{KR}$, Corbett CL. Olsalazine or sulphasalazine in first attacks of ulcerative colitis? A double-blind study. Gut 1989;30: 675-679

29. Willoughby CP, Cowan RE, Gould SR, Machell RJ, Stewart JB. Double-blind comparison of olsalazine and sulphasalazine in active ulcerative colitis. Scand J Gastroenterol Suppl 1988;148:40-44

30. Courtney MG, Nunes DP, Bergin CF, et al. Randomised comparison of olsalazine and mesalazine in prevention of relapses in ulcerative colitis. Lancet 1992;339:12791281

31. Sandberg-Gertzen H, Jarnerot G, Kraaz W. Azodisal sodium in the treatment of ulcerative colitis. A study of tolerance and relapse-prevention properties. Gastroenterology 1986;90:1024-1030

32. Meyers S, Sachar DB, Present DH, Janowitz HD. Olsalazine sodium in the treatment of ulcerative colitis among patients intolerant of sulfasalazine. A prospective, randomized, placebo-controlled, double-blind, dose-ranging clinical trial. Gastroenterology 1987;93:1255-1262

33. Green JR, Lobo AJ, Holdsworth CD, et al. Balsalazide is more effective and better tolerated than mesalamine in the treatment of acute ulcerative colitis. The Abacus Investigator Group. Gastroenterology 1998;114:15-22
34. Green JR, Mansfield JC, Gibson JA, Kerr GD, Thornton PC. A double-blind comparison of balsalazide, $6.75 \mathrm{~g}$ daily, and sulfasalazine, $3 \mathrm{~g}$ daily, in patients with newly diagnosed or relapsed active ulcerative colitis. Aliment Pharmacol Ther 2002;16:61-68

35. Levine DS, Riff DS, Pruitt R, et al. A randomized, double blind, dose-response comparison of balsalazide $(6.75 \mathrm{~g})$, balsalazide $(2.25 \mathrm{~g})$, and mesalamine $(2.4 \mathrm{~g})$ in the treatment of active, mild-to-moderate ulcerative colitis. Am J Gastroenterol 2002;97:1398-1407

36. Pruitt R, Hanson J, Safdi M, et al. Balsalazide is superior to mesalamine in the time to improvement of signs and symptoms of acute mild-to-moderate ulcerative colitis. Am J Gastroenterol 2002;97:3078-3086

37. Bitton A, Peppercorn MA, Hanrahan JP, Upton MP. Mesalamine-induced lung toxicity. Am J Gastroenterol 1996;91:1039-1040

38. Iaquinto G, Sorrentini I, Petillo FE, Berardesca G. Pleuropericarditis in a patient with ulcerative colitis in longstanding 5-aminosalicylic acid therapy. Ital J Gastroenterol 1994;26: 145-147

39. Deltenre P, Berson A, Marcellin P, Degott C, Biour M, Pessayre D. Mesalazine (5-aminosalicylic acid) induced chronic hepatitis. Gut 1999;44:886-888

40. Fernandez J, Sala M, Panes J, Feu F, Navarro S, Teres J. Acute pancreatitis after long-term 5-aminosalicylic acid therapy. Am J Gastroenterol 1997;92:2302-2303

41. Brouillard M, Gheerbrant JD, Gheysens Y, et al. Chronic interstitial nephritis and mesalazine: 3 new cases? [in French]. Gastroenterol Clin Biol 1998;22:724-726

42. Hanauer SB, Verst-Brasch C, Regalli G. Renal safety of long-term mesalamine therapy in inflammatory bowel disease (IBD). Gastroenterology 1997;112:A991

43. Marteau P, Nelet F, Le Lu M, Devaux C. Adverse events in patients treated with 5-aminosalicyclic acid: 1993-1994 pharmacovigilance report for Pentasa in France. Aliment Pharmacol Ther 1996;10:949-956

43a. Sturgeon JB, Bhatia P, Hermens D, Miner PB Jr. Exacerbation of chronic ulcerative colitis with mesalamine. Gastroenterology 1995;108:1889-1893

44. Edwards F, Truelove SC. The course and prognosis of ulcerative colitis. Gut 1963;41:299-315

45. Ekbom A, Helmick CG, Zack M, Holmberg L, Adami HO. Survival and causes of death in patients with inflammatory bowel disease: a population-based study. Gastroenterology 1992;103:954-960

46. Faubion WA Jr, Loftus EV Jr, Harmsen WS, Zinsmeister AR, Sandborn WJ. The natural history of corticosteroid therapy for inflammatory bowel disease: a population-based study. Gastroenterology 2001;121:255-260

47. Munkholm P, Langholz E, Davidsen M, Binder V. Frequency of glucocorticoid resistance and dependency in Crohn's disease. Gut 1994;35:360-362

48. Honda M, Orii F, Ayabe T, et al. Expression of glucocorticoid receptor beta in lymphocytes of patients with glucocorticoid-resistant ulcerative colitis. Gastroenterology 2000;118:859-866

49. Farrell RJ, Murphy A, Long A, et al. High multidrug resistance (P-glycoprotein 170) expression in inflammatory bowel disease patients who fail medical therapy. Gastroenterology 2000;118:279-288

50. Baron JH, Connell AM, Kanaghinis TG, Lennard-Jones JE, Jones AF. Out-patient treatment of ulcerative colitis. 
Comparison between three doses of oral prednisone. BMJ 1962; 5302:441-443

51. Powell-Tuck J, Bown RL, Lennard-Jones JE. A comparison of oral prednisolone given as single or multiple daily doses for active proctocolitis. Scand J Gastroenterol 1978;13:833837

52. Lennard-Jones JE, Misiewicz JJ, Connell AM, Baron JH, Avery Jones F. Prednisone as maintenance treatment for ulcerative colitis in remission. Lancet 1965;191:188-189

53. Watkinson G. Treatment of ulcerative colitis with topical hydrocortisone hemisuccinate sodium A controlled trial employing restricted sequential analysis. BMJ 1958;1077-1082

54. Lennard-Jones JE, Baron JH, Connell AM, et al. A double blind controlled trial of prednisolone-21-phosphate suppositories in the treatment of idiopathic proctitis. Gut 1962;3: 207-210

55. Truelove S. Treatment of ulcerative colitis with local hydrocortisone hemisuccinate sodium. A report on a controlled therapeutic trial. BMJ 1958;1072-1077

56. Lindgren S, Lofberg R, Bergholm L, et al. Effect of budesonide enema on remission and relapse rate in distal ulcerative colitis and proctitis. Scand J Gastroenterol 2002; 37:705-710

57. Cohen RD, Woseth DM, Thisted RA, Hanauer SB. A meta-analysis and overview of the literature on treatment options for left-sided ulcerative colitis and ulcerative proctitis. Am J Gastroenterol 2000;95:1263-1276

58. Farmer RG, Schumacher OP. Treatment of ulcerative colitis with hydrocortisone enemas. Comparison of absorption and clinical response with hydrocortisone alcohol and hydrocortisone acetate. Am J Gastroenterol 1970;54:229-236

59. Elliott PR, Powell-Tuck J, Gillespie PE, et al. Prednisolone absorption in acute colitis. Gut 1980;21:49-51

60. Truelove SC, Jewell DP. Intensive intravenous regimen for severe attacks of ulcerative colitis. Lancet 1974;1:1067-1070

61. Rizzello F, Gionchetti P, Venturi A, Campieri M. Medical treatment of severe ulcerative colitis. Aliment Pharmacol Ther 2003;17(suppl 2):7-10

62. Meyers S, Sachar DB, Goldberg JD, Janowitz HD. Corticotropin versus hydrocortisone in the intravenous treatment of ulcerative colitis. A prospective, randomized, doubleblind clinical trial. Gastroenterology 1983;85:351-357

63. Powell-Tuck J, Buckell NA, Lennard-Jones JE. A controlled comparison of corticotropin and hydrocortisone in the treatment of severe proctocolitis. Scand J Gastroenterol 1977;12: 971-975

64. Kaplan HP, Portnoy B, Binder HJ, Amatruda T, Spiro H. A controlled evaluation of intravenous adrenocorticotropic hormone and hydrocortisone in the treatment of acute colitis. Gastroenterology 1975;69:91-95

65. Talar-Williams C, Sneller MC. Complications of corticosteroid therapy. Eur Arch Otorhinolaryngol 1994;251:131-136

66. Singleton JW, Law DH, Kelley ML Jr, Mekhjian HS, Sturdevant RA. National Cooperative Crohn's Disease Study: adverse reactions to study drugs. Gastroenterology 1979;77:870-882

67. Kusunoki M, Moeslein G, Shoji Y, et al. Steroid complications in patients with ulcerative colitis. Dis Colon Rectum 1992;35:1003-1009

68. Turunen UM, Farkkila MA, Hakala K, et al. Long-term treatment of ulcerative colitis with ciprofloxacin: a prospective, double-blind, placebo-controlled study. Gastroenterology 1998;115:1072-1078
69. Mantzaris GJ, Archavlis E, Christoforidis P, et al. A prospective randomized controlled trial of oral ciprofloxacin in acute ulcerative colitis. Am J Gastroenterol 1997;92:454-456

70. Mantzaris GJ, Petraki K, Archavlis E, et al. A prospective randomized controlled trial of intravenous ciprofloxacin as an adjunct to corticosteroids in acute, severe ulcerative colitis. Scand J Gastroenterol 2001;36:971-974

71. Burke DA, Axon AT, Clayden SA, Dixon MF, Johnston D, Lacey RW. The efficacy of tobramycin in the treatment of ulcerative colitis. Aliment Pharmacol Ther 1990;4:123-129

72. Lobo AJ, Burke DA, Sobala GM, Axon AT. Oral tobramycin in ulcerative colitis: effect on maintenance of remission. Aliment Pharmacol Ther 1993;7:155-158

73. Mantzaris GJ, Hatzis A, Kontogiannis P, Triadaphyllou G. Intravenous tobramycin and metronidazole as an adjunct to corticosteroids in acute, severe ulcerative colitis. Am J Gastroenterol 1994;89:43-46

74. Dickinson RJ, O'Connor HJ, Pinder I, Hamilton I, Johnston D, Axon AT. Double blind controlled trial of oral vancomycin as adjunctive treatment in acute exacerbations of idiopathic colitis. Gut 1985;26:1380-1384

75. Chapman RW, Selby WS, Jewell DP. Controlled trial of intravenous metronidazole as an adjunct to corticosteroids in severe ulcerative colitis. Gut 1986;27:1210-1212

76. Gionchetti P, Rizzello F, Ferrieri A, et al. Rifaximin in patients with moderate or severe ulcerative colitis refractory to steroid-treatment: a double-blind, placebo-controlled trial. Dig Dis Sci 1999;44:1220-1221

77. Gionchetti P, Rizzello F, Helwig U, et al. Prophylaxis of pouchitis onset with probiotic therapy: a double-blind, placebo-controlled trial. Gastroenterology 2003;124:12021209

78. Gionchetti P, Rizzello F, Venturi A, et al. Oral bacteriotherapy as maintenance treatment in patients with chronic pouchitis: a double-blind, placebo-controlled trial. Gastroenterology 2000;119:305-309

79. Rembacken BJ, Snelling AM, Hawkey PM, Chalmers DM, Axon AT. Non-pathogenic Escherichia coli versus mesalazine for the treatment of ulcerative colitis: a randomised trial. Lancet 1999;354:635-639

80. Kruis W, Schutz E, Fric P, Fixa B, Judmaier G, Stolte M. Double-blind comparison of an oral Escherichia coli preparation and mesalazine in maintaining remission of ulcerative colitis. Aliment Pharmacol Ther 1997;11:853-858

81. Fedorak R, Gionchetti P, Campieri M, Madsen K, Isaacs K. VSL3 probiotic mixture induces remission in patients with active ulcerative colitis. Gastroenterology 2003;124:A-377

82. Beaugerie L, Massot N, Carbonnel F, Cattan S, Gendre JP, Cosnes J. Impact of cessation of smoking on the course of ulcerative colitis. Am J Gastroenterol 2001;96:2113-2116

83. Green JT, Richardson C, Marshall RW, et al. Nitric oxide mediates a therapeutic effect of nicotine in ulcerative colitis. Aliment Pharmacol Ther 2000;14:1429-1434

84. Sandborn WJ. Nicotine therapy for ulcerative colitis: a review of rationale, mechanisms, pharmacology, and clinical results. Am J Gastroenterol 1999;94:1161-1171

85. Pullan RD, Rhodes J, Ganesh S, et al. Transdermal nicotine for active ulcerative colitis. N Engl J Med 1994;330:811815

86. Sandborn WJ, Tremaine WJ, Offord KP, et al. Transdermal nicotine for mildly to moderately active ulcerative colitis. A randomized, double-blind, placebo-controlled trial. Ann Intern Med 1997;126:364-371 
87. Thomas GA, Rhodes J, Mani V, et al. Transdermal nicotine as maintenance therapy for ulcerative colitis. $\mathrm{N}$ Engl J Med 1995;332:988-992

88. Guslandi M. Long-term effects of a single course of nicotine treatment in acute ulcerative colitis: remission maintenance in a 12-month follow-up study. Int J Colorectal Dis 1999;14: 261-262

89. Green JT, Thomas GA, Rhodes J, et al. Nicotine enemas for active ulcerative colitis - a pilot study. Aliment Pharmacol Ther 1997;11:859-863

90. Sandborn WJ, Tremaine WJ, Leighton JA, et al. Nicotine tartrate liquid enemas for mildly to moderately active leftsided ulcerative colitis unresponsive to first-line therapy: a pilot study. Aliment Pharmacol Ther 1997;11:663-671

91. Bean R. The treatment of chronic ulcerative colitis with 6-mercaptopurine. Med J Aust 1962;49:592-593

92. Jewell DP, Truelove SC. Azathioprine in ulcerative colitis: final report on controlled therapeutic trial. BMJ 1974;4:627630

93. Kirk AP, Lennard-Jones JE. Controlled trial of azathioprine in chronic ulcerative colitis. Br Med J (Clin Res Ed) 1982; 284:1291-1292

94. Hawthorne AB, Logan RF, Hawkey CJ, et al. Randomised controlled trial of azathioprine withdrawal in ulcerative colitis. BMJ 1992;305:20-22

95. Ardizzone S, Molteni P, Imbesi V, Bollani S, Bianchi Porro G, Molteni F. Azathioprine in steroid-resistant and steroiddependent ulcerative colitis. J Clin Gastroenterol 1997;25: 330-333

96. Lobo AJ, Foster PN, Burke DA, Johnston D, Axon AT. The role of azathioprine in the management of ulcerative colitis. Dis Colon Rectum 1990;33:374-377

97. Steinhart AH, Baker JP, Brzezinski A, Prokipchuk EJ. Azathioprine therapy in chronic ulcerative colitis. J Clin Gastroenterol 1990;12:271-275

98. Korelitz BI, Adler DJ, Mendelsohn RA, Sacknoff AL. Longterm experience with 6-mercaptopurine in the treatment of Crohn's disease. Am J Gastroenterol 1993;88:1198-1205

99. George J, Present DH, Pou R, Bodian C, Rubin PH. The long-term outcome of ulcerative colitis treated with 6mercaptopurine. Am J Gastroenterol 1996;91:1711-1714

100. Pearson DC, May GR, Fick GH, Sutherland LR. Azathioprine and 6-mercaptopurine in Crohn's disease. A meta-analysis. Ann Intern Med 1995;123:132-142

101. Mahadevan U, Tremaine WJ, Johnson T, et al. Intravenous azathioprine in severe ulcerative colitis: a pilot study. Am J Gastroenterol 2000;95:3463-3468

102. Black AJ, McLeod HL, Capell HA, et al. Thiopurine methyltransferase genotype predicts therapy-limiting severe toxicity from azathioprine. Ann Intern Med 1998;129:716718

103. Colombel JF, Ferrari N, Debuysere H, et al. Genotypic analysis of thiopurine S-methyltransferase in patients with Crohn's disease and severe myelosuppression during azathioprine therapy. Gastroenterology 2000;118:1025-1030

104. Snow JL, Gibson LE. A pharmacogenetic basis for the safe and effective use of azathioprine and other thiopurine drugs in dermatologic patients. J Am Acad Dermatol 1995;32:114116

105. Dubinsky MC, Lamothe S, Yang HY, et al. Pharmacogenomics and metabolite measurement for 6-mercaptopurine therapy in inflammatory bowel disease. Gastroenterology 2000;118:705-713
106. Cuffari C, Theoret Y, Latour S, Seidman G. 6-mercaptopurine metabolism in Crohn's disease: correlation with efficacy and toxicity. Gut 1996;39:401-406

107. Lowry PW, Franklin CL, Weaver AL, et al. Measurement of thiopurine methyltransferase activity and azathioprine metabolites in patients with inflammatory bowel disease. Gut 2001;49:665-670

108. Belaiche J, Desager JP, Horsmans Y, Louis E. Therapeutic drug monitoring of azathioprine and 6-mercaptopurine metabolites in Crohn's disease. Scand J Gastroenterol 2001;36:71-76

109. Sandborn WJ, Tremaine WJ, Wolf DC, et al. Lack of effect of intravenous administration on time to respond to azathioprine for steroid-treated Crohn's disease North American Azathioprine Study Group. Gastroenterology 1999;117:527-535

110. Present DH, Meltzer SJ, Krumholz MP, Wolke A, Korelitz BI. 6-mercaptopurine in the management of inflammatory bowel disease: short- and long-term toxicity. Ann Intern Med 1989;111:641-649

111. Connell WR, Kamm MA, Dickson M, Balkwill AM, Ritchie JK, Lennard-Jones JE. Long-term neoplasia risk after azathioprine treatment in inflammatory bowel disease. Lancet 1994;343:1249-1252

112. Fraser AG, Orchard TR, Robinson EM, Jewell DP. Longterm risk of malignancy after treatment of inflammatory bowel disease with azathioprine. Aliment Pharmacol Ther 2002;16:1225-1232

113. Dayharsh GA, Loftus EV Jr, Sandborn WJ, et al. EpsteinBarr virus-positive lymphoma in patients with inflammatory bowel disease treated with azathioprine or 6-mercaptopurine. Gastroenterology 2002;122:72-77

114. Feagan BG, Fedorak RN, Irvine EJ, et al. A comparison of methotrexate with placebo for the maintenance of remission in Crohn's disease. North American Crohn's Study Group Investigators. N Engl J Med 2000;342:16271632

115. Feagan BG, Rochon J, Fedorak RN, et al. Methotrexate for the treatment of Crohn's disease. North American Crohn's Study Group Investigators. N Engl J Med 1995;332:292297

116. Egan LJ, Tremaine WJ, Mays DC, Lipsky JJ, Sandborn WJ. Clinical outcome and pharmacokinetics after addition of low-dose cyclosporine to methotrexate: a case study of five patients with treatment-resistant inflammatory bowel disease. Inflamm Bowel Dis 2000;6:286-289

117. Baron TH, Truss CD, Elson CO. Low-dose oral methotrexate in refractory inflammatory bowel disease. Dig Dis Sci 1993;38:1851-1856

118. Kozarek RA, Patterson DJ, Gelfand MD, Botoman VA, Ball TJ, Wilske KR. Methotrexate induces clinical and histologic remission in patients with refractory inflammatory bowel disease. Ann Intern Med 1989;110:353-356

119. Oren R, Arber N, Odes S, et al. Methotrexate in chronic active ulcerative colitis: a double-blind, randomized, Israeli multicenter trial. Gastroenterology 1996;110:14161421

120. Paoluzi OA, Pica R, Marcheggiano A, et al. Azathioprine or methotrexate in the treatment of patients with steroiddependent or steroid-resistant ulcerative colitis: results of an open-label study on efficacy and tolerability in inducing and maintaining remission. Aliment Pharmacol Ther 2002;16: 1751-1759 
121. Lichtiger S, Present DH, Kornbluth A, et al. Cyclosporine in severe ulcerative colitis refractory to steroid therapy. N Engl J Med 1994;330:1841-1845

122. Svanoni F, Bonassi U, Bagnolo F, et al. Effectiveness of cyclosporoine $\mathrm{A}(\mathrm{Cs} \mathrm{A})$ in the treatment of active refractory ulcerative colitis. Gastroenterology 1998;114:A1096

123. D'Haens G, Lemmens L, Geboes K, et al. Intravenous cyclosporine versus intravenous corticosteroids as single therapy for severe attacks of ulcerative colitis. Gastroenterology 2001;120:1323-1329

124. Van Assche G, D’Haens G, Noman M, et al. Randomized, double-blind comparison of $4 \mathrm{mg} / \mathrm{kg}$ versus $2 \mathrm{mg} / \mathrm{kg}$ intravenous cyclosporine in severe ulcerative colitis. Gastroenterology 2003;125:1025-1031

125. Kornbluth A, Present DH, Lichtiger S, Hanauer S. Cyclosporin for severe ulcerative colitis: a user's guide. Am J Gastroenterol 1997;92:1424-1428

126. Cohen RD, Stein R, Hanauer SB. Intravenous cyclosporin in ulcerative colitis: a five-year experience. Am J Gastroenterol 1999;94:1587-1592

127. Domenech E, Garcia-Planella E, Bernal I, et al. Azathioprine without oral ciclosporin in the long-term maintenance of remission induced by intravenous ciclosporin in severe, steroid-refractory ulcerative colitis. Aliment Pharmacol Ther 2002;16:2061-2065

128. Sandborn WJ. Cyclosporine in ulcerative colitis: state of the art. Acta Gastroenterol Belg 2001;64:201-204

129. Latteri M, Angeloni TG, Silveri NG, Manna R, Gasbarrini G, Navarra P. Pharmacokinetics of cyclosporin microemulsion in patients with inflammatory bowel disease. Clin Pharmacokinet 2001;40:473-483

130. Actis GC, Aimo G, Priolo G, Moscato D, Rizzetto M, Pagni R. Efficacy and efficiency of oral microemulsion cyclosporin versus intravenous and soft gelatin capsule cyclosporin in the treatment of severe steroid-refractory ulcerative colitis: an open-label retrospective trial. Inflamm Bowel Dis 1998;4:276-279

131. Navazo L, Salata H, Morales S, et al. Oral microemulsion cyclosporine in the treatment of steroid-refractory attacks of ulcerative and indeterminate colitis. Scand J Gastroenterol 2001;36:610-614

132. Sood A, Midha V, Sood N. Oral cyclosporine in patients with active severe ulcerative colitis not responding to steroids. Indian J Gastroenterol 2002;21:155-156

133. Sternthal MGJ, Kornbluth A. Toxicity associated with the use of cyclosporin in patients with inflammatory bowel disease. Gastroenterology 1996;110:A1019

134. Bousvaros A, Kirschner BS, Werlin SL, et al. Oral tacrolimus treatment of severe colitis in children. J Pediatr 2000;137:794-799

135. Baumgart DC, Wiedenmann B, Dignass AU. Rescue therapy with tacrolimus is effective in patients with severe and refractory inflammatory bowel disease. Aliment Pharmacol Ther 2003;17:1273-1281

136. Matsuhashi N, Nakajima A, Watanabe K, et al. Tacrolimus in corticosteroid-resistant ulcerative colitis. J Gastroenterol 2000;35:635-640

137. Pascu M, Muller AR, Wiedenmann B, Dignass AU. Rescue therapy with tacrolimus in a patient with toxic megacolon. Int J Colorectal Dis 2003;18:271-275

138. Fellermann K, Tanko Z, Herrlinger KR, et al. Response of refractory colitis to intravenous or oral tacrolimus (FK506). Inflamm Bowel Dis 2002;8:317-324
139. Hanauer SLG, Colombel JF, et al. Maintenance infliximab (Remicade) is safe, effective and steroid-sparing in Crohn's disease: preliminary results of the Accent I trial. Gastroenterology 2001;120:A-21:

140. Sands BE, Tremaine WJ, Sandborn WJ, et al. Infliximab in the treatment of severe, steroid-refractory ulcerative colitis: a pilot study. Inflamm Bowel Dis 2001;7:83-88

141. Chey WY, Hussain A, Ryan C, Potter GD, Shah A. Infliximab for refractory ulcerative colitis. Am J Gastroenterol 2001;96:2373-2381

142. Kaser A, Mairinger T, Vogel W, Tilg H. Infliximab in severe steroid-refractory ulcerative colitis: a pilot study. Wien Klin Wochenschr 2001;113:930-933

143. Probert C, Hearing SD, Shreiber S, Kuhbacher T, Ghosh S, Forbes A. Infliximab in steroid-resistant ulcerative colitis: a randomized controlled trial. Gastroenterology 2002;122:A99

144. Ochsenkuhn T, Sackmann M, Goeke B. Infliximab for acute severe uclerative colitis: a randomized pilot study in nonsteroid refractory patients. Gastroenterology 2003;124: A62

145. Su C, Salzberg BA, Lewis JD, et al. Efficacy of anti-tumor necrosis factor therapy in patients with ulcerative colitis. Am J Gastroenterol 2002;97:2577-2584

146. Dhillon AP, Anthony A, Sim R, et al. Mucosal capillary thrombi in rectal biopsies. Histopathology 1992;21:127133

147. Gaffney PR, Doyle CT, Gaffney A, Hogan J, Hayes DP, Annis P. Paradoxical response to heparin in 10 patients with ulcerative colitis. Am J Gastroenterol 1995;90:220-223

148. Evans RC, Wong VS, Morris AI, Rhodes JM. Treatment of corticosteroid-resistant ulcerative colitis with heparin-a report of 16 cases. Aliment Pharmacol Ther 1997;11:10371040

149. Panes J, Esteve M, Cabre E, et al. Comparison of heparin and steroids in the treatment of moderate and severe ulcerative colitis. Gastroenterology 2000;119:903-908

150. Ang YS, Mahmud N, White B, et al. Randomized comparison of unfractionated heparin with corticosteroids in severe active inflammatory bowel disease. Aliment Pharmacol Ther 2000;14:1015-1022

151. Bloom S, Kiilerich S, Lassen MR, O’Morain C, Forbes A, Orm S. Randomized trial of tinzaparin, a low molecular weight heparin (LMWH), versus placebo in the treatment of mild to moderately active ulcerative colitis. Gastroenterology 2003;124:A67

152. Korzenik J, Miner P, Stanton D, et al. Multicenter, randomized, double-blind, placebo-controlled trial of Deligoparin (ultra low molecular weight heparin) for active ulcerative colitis. Gastroenterology 2003;124:A67

153. Tuvlin JA, Kane SV. Novel therapies in the treatment of ulcerative colitis. Expert Opin Investig Drugs 2003;12:483490

154. Creed T, Hearing S, Probert C, Norman M, Dayan C. Basiliximab (IL-2 receptor antagonist) as a steroid sensitizing. Gastroenterology 2003;124:A7

155. Plevy S, Salzberg BA, Regueiro M, et al. A humanized antiCD3 monoclonal antibody, visilizumab, for treatment of severe steroid-refractory ulcerative colitis: preliminary results of a phase I study. Gastroenterology 2003;124:A7

156. Feagan B, Greenberg G, Wild G, et al. A randomized controlled trial of a humanized $\alpha 4 \beta 7$ antibody in ulcerative colitis. Gastroenterology 2003;124:Abstract: 
157. Musch E, Raedler A, Andus T, et al. A phase II placebocontrolled, randomized, multicenter study to evaluate efficacy and safety of interferon beta- $1 \mathrm{a}$ in patients with ulcerative colitis. Gastroenterology 2002;122:A431

158. Sawada K, Ohnishi K, Fukui S, et al. Leukocytapheresis therapy, performed with leukocyte removal filter, for inflammatory bowel disease. J Gastroenterol 1995;30:322329

159. Sawada K, Muto T, Shimoyama T, et al. Multicenter randomized controlled trial for the treatment of ulcerative colitis with a leukocytapheresis column. Curr Pharm Des 2003;9:307-321
160. Sawada K, Kusugam K, Suzuki Y. Multicenter randomized double blind controlled trial for ulcerative colitis therapy with leukocytapheresis. Gastroenterology 2003;124:A67

161. Cottone M, Pietrosi G, Martorana G, et al. Prevalence of cytomegalovirus infection in severe refractory ulcerative and Crohn's colitis. Am J Gastroenterol 2001;96:773-775

162. Mahadevan U, Loftus EV Jr, Tremaine WJ, et al. Azathioprine or 6-mercaptopurine before colectomy for ulcerative colitis is not associated with increased postoperative complications. Inflamm Bowel Dis 2002;8:311-316

163. Yang YX, Lichtenstein GR. Corticosteroids in Crohn's disease. Am J Gastroenterol 2002;97:803-823 